\title{
Enhancing Student Teachers' Teaching Skills through a Blended Learning Approach
}

\author{
Abeer Abdalhalim Albhnsawy ${ }^{1}(\mathrm{PhD}) \&$ Professor Ahmed Mahmoud Aliweh ${ }^{2}$ \\ ${ }^{1}$ Department of Learning and Instruction, Faculty of Education, Tanta University, Egypt \\ ${ }^{2}$ Professor of TEFL, Department of Learning and Instruction, Faculty of Education, Tanta University, Egypt \\ Correspondence: Abeer Abdalhalim Albhnsawy, (PhD), Department of Learning and Instruction, Faculty of \\ Education, Tanta University, Egypt
}

Received: July 4, 2016

doi:10.5430/ijhe.v5n3p131
Accepted: July 31, 2016

Online Published: August 5, 2016

\begin{abstract}
This study investigated the effect of a blended learning program on student teachers' teaching skills in an undergraduate microteaching course. The blended learning program lasted for nine weeks. This program aimed at integrating social network tasks and face-to-face teaching activities. Pre-and post-tests were administered to assess student teachers' micro-teaching performance. Data analysis revealed that blended learning has a significant effect on the participants' teaching skills. Relevant interpretations and recommendations were offered.
\end{abstract}

Keywords: Blended Learning, Microteaching Skills, Student teachers

\section{Introduction}

Teacher education involves a plethora of techniques and procedures for efficient preparation of student-teachers in practical subjects to provide them with the knowledge and skills which help them to teach effectively (Mannathoko, 2013). In recent years, the traditional classroom teaching cannot cater for the requirements of individual and societal needs. Therefore, teachers should explore innovative teaching techniques that make use of modern technology (Aydin, 2013).

Today, a major objective of higher educational institutions is to prepare students for survival in the digital era. To this end, students have to develop the literacy competencies they need to live, learn, and work successfully in a rapidly changing society. Consequently, this requires a shift to the constructivist information-processing paradigm (Shana, 2009). The theoretical foundations of information and communication technology (ICT) projects are based on Vygotsky's cultural-historical perspective and Wenger and Lave's situated learning theory. This paradigm perceives learning as an active and communal process whereby students build knowledge and construct meaning through interaction with others (Pletka, 2007).

The Constructivist theory asserts that knowledge is not conveyed directly from the teacher to the learner, but it is constructed by learners. Within this epistemology, learning is an active process in which meaning comes from experience (Chandlera, Parkb, Levinc \& Morse, 2013). Therefore, the learning environment requires effective experiences where learners play an active role in the teaching and learning process. This learning environment should provide opportunities to generate and construct new knowledge through the interaction between instructors, learners, and the learning materials (Shana, 2009).

Teacher educators face challenges to produce a new generation of teachers capable of addressing the demands of the 21 century classrooms. Thus, microteaching that integrates various means of technology is a promising professional development that could provide teachers with the experiences to confront these challenges (Diana, 2013). Microteaching is a pivotal experience that provides students with opportunities to practice teaching skills in an authentic environment. In other words, it helps students gain professional experience as it enables them to apply theoretical knowledge, plan and implement new teaching strategies, and reflect on their performance (Bakır, 2014; Sen, 2009). Students can practice their teaching skills in a supportive and authentic environment. Moreover, microteaching helps students to gain insights into their teaching and become engaged in more reflective practices (Donnelly \& Fitzmaurice, 2011). 
In Egypt, microteaching is a major requirement for students at faculties of education. It aims at helping student teachers acquire the basic teaching skills in various study fields.

Blended-learning can be seen as a combination of both traditional teaching and the e-learning environments; it can merge web-based instruction, videos, audio, synchronous, and asynchronous communication with face-to-face learning (Quevedo, 2011). Thus, blended learning refers to the inclusion of e-learning resources in the design and delivery of subjects through face-to-face settings (Gomez \& Duart, 2012). In other words, blended learning is the thoughtful fusion of face-to-face and online learning experience. The basic principle is that face-to-face and online activities are optimally integrated into a unique learning experience congruent with the context and the intended educational purposes (Garrison \& Vaughan, 2008).

In the current study, the researchers perceive blended learning as an approach, which integrates web- based- learning into face-to-face setting in order to provide students with resources, activities, tasks, presentations, discussions, evaluation, and constructive feedback. Thus, it aims at offering students opportunities for practicing and consolidating the teaching skills necessary for future careers.

However, to integrate online and face-to-face media, instructors should invest the available resources and optimize them in synchronous and asynchronous environments. Specifically, instructors could develop tasks where some aspects are to be completed online and others through a face-to-face setting (Shana, 2009).

The inclusion of digital content allows participants to perform tasks asynchronously at their own pace and receive constructive feedback. Yet, the absence of meaningful face-to-face social interaction may impede the entire online learning process (Chandlera et al., 2013).

In fact, various studies conducted in Egypt showed that there is a gap in teacher preparation programs. Therefore, the inclusion of multi-modals of technology is imperative in order to promote prospective teachers' skills and competencies. In particular, the integration of modern technology into microteaching programs might help overcome the challenges that students face at various Egyptian educational institutions (Diana, 2013).

\subsection{Statement of the problem}

This study examined the impact of integrating a blended learning program into a microteaching course offered to student teachers majoring in Science Education. These students seem to lack the basic skills of teaching in the digital era. To be more specific, this study addressed the following questions:

\subsection{Questions}

1) What is the effectiveness of a blended learning program on students' teaching skills?

Sub-Questions:

a. What is the effectiveness of this blended learning program on achieving the instructional objectives?

B. What is the effectiveness of this blended learning program on students' content analysis skill?

C. What is the effectiveness of this blended learning program on students' lesson planning skill?

\subsection{Aim of the Study}

This study aimed at enhancing student teachers' instructional skills through using a blended learning program which included presentations, videos, activities, and other technological resources.

\section{Method}

\subsection{Sample}

This study was conducted on 24 participants majoring in Science Education at the Faculty of Education, Tanta University, Egypt. The average age of these sophomores was 20 years. The participants were enrolled in a four year undergraduate program that prepares them for teaching at both governmental and private schools.

\subsection{Instruments}

Pre- and post-tests were developed by the investigator in order to assess the participants' teaching skills. These tests included 23 performance tasks that students had to carry out. These tasks required the participants to apply the skills of teaching science at preparatory schools. To be more specific, these tasks examined the following three skills:

1) Instructional objectives (16 tasks)

(2) Content analysis (6 tasks) 
(3) Lesson planning: It included one task with eight subtasks which addressed various dimensions of lesson planning. Test reliability was examined by administering the Cronbach Alpha coefficient which yielded a 0.83 value.

\subsection{Implementation}

This study lasted for nine weeks. The program started on Tuesday, October $7^{\text {th }}, 2014$ and ended at January, 5th, 2015. As indicated earlier, the program integrated social networking activities into a face-to-face classroom. These activities focused on three major skills: 1) Instructional objectives (2) Content analysis, and (3) Lesson planning. The researchers created a Facebook group (Note 1) whose members could watch videos, presentations, and other applications. The Facebook group focused on training students to accomplish specific tasks in order to improve their teaching skills. At the end of each session, the participants performed a number of tasks which required them to apply the assigned skills. After performing the tasks, the participants uploaded them on the Facebook group. The instructor reviewed the activities offered comments on students' performance. Thus, the participants had to master the skills of uploading and downloading electronic lectures, exercises, presentations, videos, and discussions. Students had also to engage in online discussions and comments through the Facebook group. Thus, interaction among the participants was both synchronous and asynchronous. The following figure shows the roles of both the instructor and students throughout the Facebook activities:
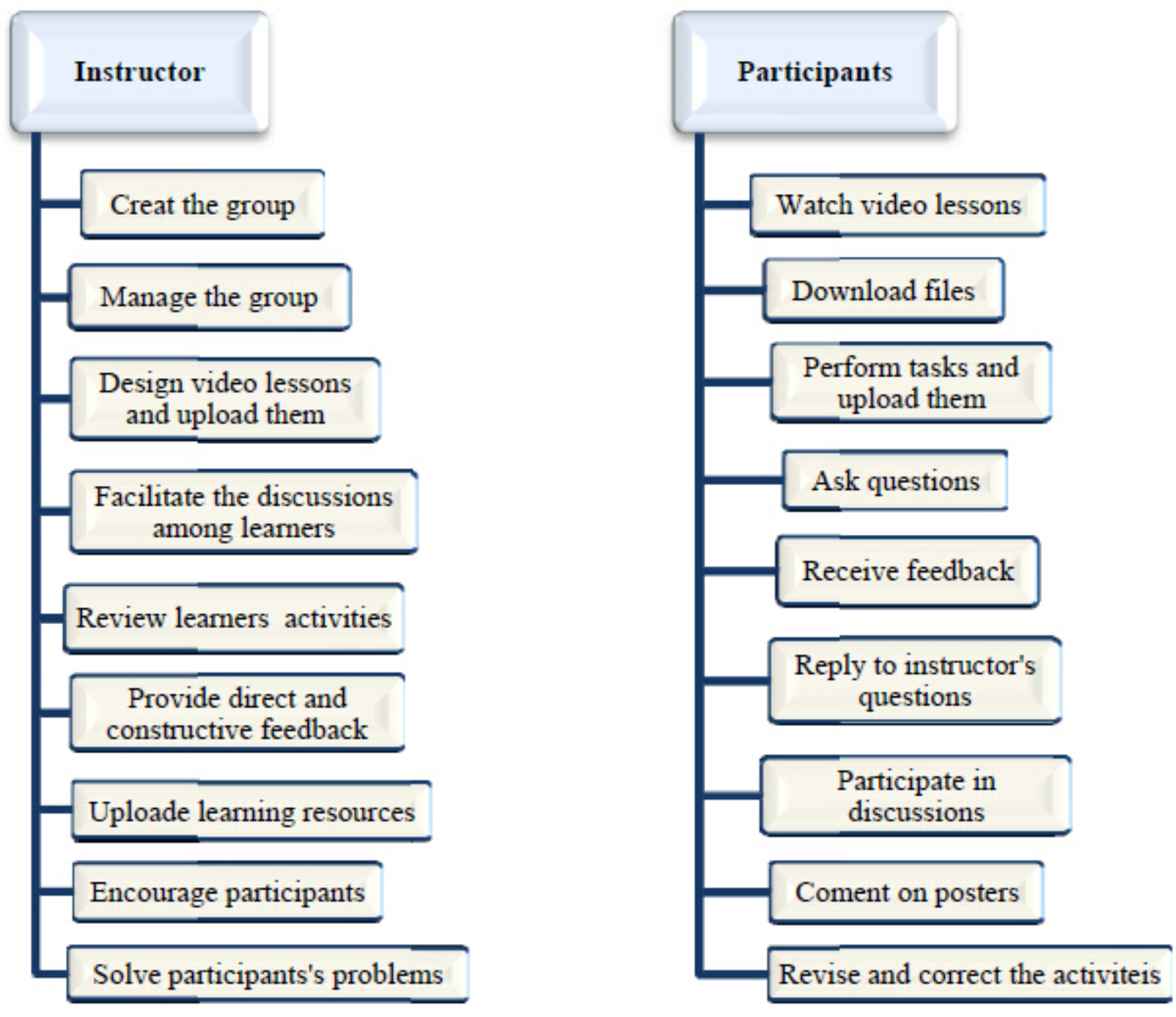

Figure 1. The roles of the instructor and the participants in the Facebook group

After each web-based learning session, there was a face-to-face teaching lesson. The face-to-face activities aimed at offering constructive feedback and motivating the participants. Also, a special care was given to helping the participants improve their performance through addressing emergent issues. 


\section{Results and Discussion}

To examine the effect of the current blended learning program on the participants' teaching skills, the $t$-test for paired samples was administered through the Statistical Package for Social Sciences (SPSS). Table (1) shows the results the $t$-test analysis.

Table 1. Mean scores of student teachers' performance on the pre-and post-tests

\begin{tabular}{l|lllllll}
\hline Teaching skills & Pre/post & $\boldsymbol{N}$ & $\boldsymbol{x}^{-}$ & SD & Df & T & $\begin{array}{l}\text { Sig } \\
\text { (2- tailed) }\end{array}$ \\
\hline \multirow{2}{*}{ instructional objectives } & Pre-test & 24 & 1.04 & 1.33 & 23 & 23.22 & $.000^{*}$ \\
& Post-test & 24 & 11.67 & 2.37 & & & \\
\multirow{2}{*}{ Content analysis } & Pre-test & 24 & 2.50 & 1.77 & 23 & 7.70 & $.000^{*}$ \\
& Post-test & 24 & 5.67 & 0.70 & & & \\
\multirow{2}{*}{ Lesson planning } & Pre-test & 24 & 0.54 & 0.51 & 23 & 29.78 & $.000^{*}$ \\
\multirow{2}{*}{$\begin{array}{l}\text { Total scores of teaching } \\
\text { skills }\end{array}$} & Post-test & 24 & 7.00 & 1.02 & & & \\
\hline & Pre-test & 24 & 3.67 & 2.55 & 23 & 31.39 & $.000^{*}$ \\
\hline
\end{tabular}

$* \mathrm{p}<0.05$

Table (1) indicates that there were statistically significant differences between the pre-test and post-test scores of the participants for the overall teaching skills $(t=31.39, p<0.05)$. Similarly, the t-test values for the three teaching sub-skills were significant: For instructional objectives $(t=23.22, p<0.05)$; for content analysis skill $(t=7.70$, $p<0.05$ ); and for lesson planning $(t=29.78, p<0.05$. Thus, it is concluded that the current blended learning micro-teaching program was effective in promoting the three teaching skills which this study handled. Figure 2 shows the participants' mean scores on the pre- and post-tests.

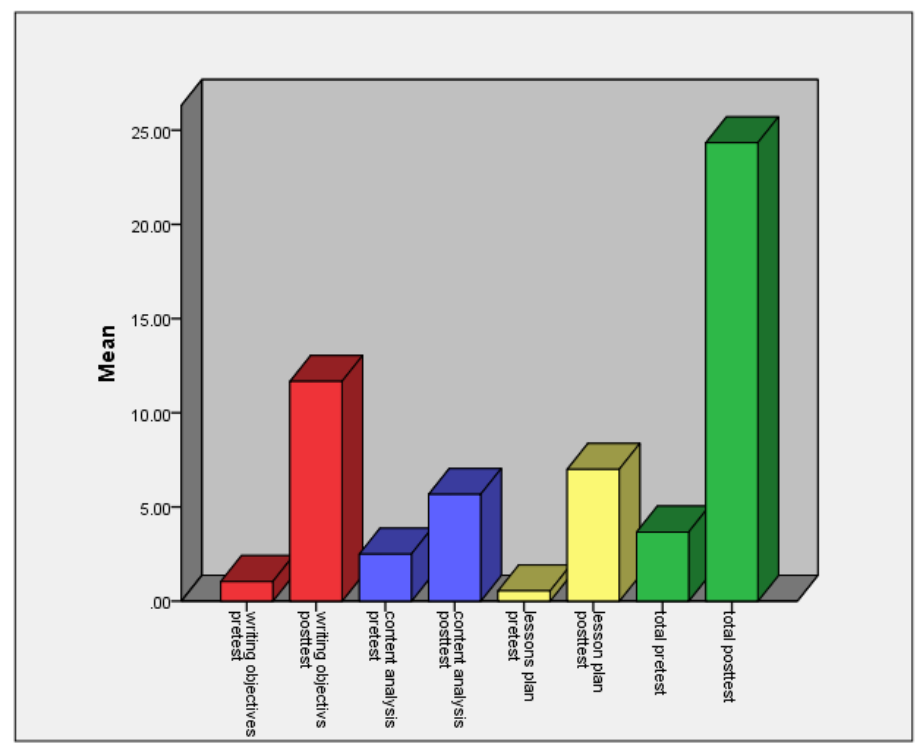

Figure 2. The participants' mean scores on the pre- and post-tests of teaching skills

In figure (2), the mean' scores of the on the pre- and post-tests indicate that the current blended learning program was effective in enhancing the participants' teaching skills. This improvement in students' teaching skills could be attributed to various reasons. Most importantly, the Facebook activities might have provided students with ideas, views, and experiences which helped promote their teaching performance. Students had the opportunity to watch videos anytime and at their ease. Besides, the participants received feedback from the instructor about the positive and negative aspects of their performance. Moreover, the face-to-face sessions allowed direct interaction among the participants. 
Yet, the current finding is consistent with Chandlera, et al. (2013) who showed that blended learning was significantly effective on the respondents' application of teaching skills. Similarly, (Lee \& Wu, 2006) indicated that the use of videos in web-based computer-mediated communication effectively enhanced pre-service teachers' teaching experience. Moreover, Smith, et al. (2012) concluded that the blended learning environment facilitated aspects of experiential learning.

Current results also agree with Quevedo (2011) who revealed that students who tended to be shy in the face - to face classroom environments felt relatively comfortable participating in discussion forums because they could work previously on the messages they wanted to post. Consequently, the respondents showed improvement in their overall performance. Likewise, Lin, et al., (2011) concluded that teacher education programs should include a combination of conventional and Web-based forms of teaching activities. In the same vein, Vogt (2014) suggested that educational institutions must have a clear plan concerning integrating blended learning programs into various fields of study. Also, Precel, et al. (2009) recommended the use of blended learning applications (videos, presentations, discussions, etc.) in order to bridge the gap between course instructors and students.

Finally, Kivunja (2013) pointed out that the social media should be utilized to promote the pedagogical practices of pre-service teacher training programs.

At the end of the experiment, the researchers conducted a group interview with the participants. Their responses supported the previous conclusion. Below are some excerpts of students' perceptions toward this blended learning program:

- " "It was nice that online activities allowed me to study the lecture any time."

- "I could repeat the video lessons many times until I fully understood it."

- $\quad$ "My parents were pleased with watching the video with me at home."

- "I enjoyed studying this course and I want to continue the same way in the second semester."

\section{Conclusion and Recommendations}

In light of current findings, it is concluded that blended learning activities are effective in promoting student teachers' teaching skills. Combining synchronous and asynchronous activities and applications offers student teachers plenty of opportunities to receive feedback and exchange views. Therefore, blended learning activities should be incorporated into pre-service teacher preparation programs. This will help student teachers overcome serious challenges they face in this digital era. However, the above conclusion should be approached with caution due to the small sample size and the short duration of the treatment. As such, it is hard to generalize current findings to other contexts because of these limitations.

Nevertheless, several issues need further investigation. Most importantly, the impact of various tools and applications on teaching strategies should be examined. Also, student teachers' perceptions of blended learning activities should be explored. Last, qualitative research methods should be used to examine the potential of blended learning activities in various fields.

\section{References}

Aydin, I. (2013). The Effect Of Microteaching Technique On Turkish Teacher Candidates' Perceptions Of Efficacy In Lesson Planning, Implementation, And Evaluation. Electronic Journal of Social Sciences, 12 (43), 67-81. Retrieved from: www.esosder.org

Bakır, S. (2014). The Effect of Microteaching on the Teaching Skills of Pre-service Science Teachers. Journal of Baltic Science Education, 13 (6), 789- 801.

Chandlera, T., Parkb, y., Levinc, K. \& Morse, S. (2013). The incorporation of hands-on tasks in an online course: an analysis of a blended learning environment. Interactive Learning Environments, 21 (5), 456-468. http://dx.doi.org/10.1080/10494820.2011.593524

Diana, T. (2013). Microteaching revisited using technology to enhance the professional development of pre-service teachers, Clearing House, 86 (4), pp. 150-154. http://dx.doi.org/10.1080/00098655.2013.790307

Donnelly, R. \& Fitzmaurice, M. (2011). Towards productive reflective practice in microteaching. Innovations in Education and Teaching International, 48 (3), 335-346. http://dx.doi.org/10.1080/14703297.2011.593709

Garrison, R. and Vaughan, N. (2008). Blended learning in higher education: Framework, principles, and guidelines, San Francisco, CA: Jossey-Bass. 
Gomez, L. \& Duart, J. (2012). A hybrid approach to university subject learning activities. British Journal of Educational Technology, 43 (2), 259-271. http://dx.doi.org/10.1111/j.1467-8535.2011.01175.x

Kivunja, C. (2013). Embedding Digital Pedagogy in Pre-Service Higher Education To Better Prepare Teachers for the Digital Generation. International Journal of Higher Education, 2 (4), 131- 142. http://dx.doi.org/10.5430/ijhe.v2n4p131

Lee, G. C. \& Wu, C. C. (2006). Enhancing the teaching experience of pre-service teachers through the use of videos in web-based computer-mediated communication (CMC). Innovations in Education and Teaching International, 43 (4), 369-380. http://dx.doi.org/10.1080/14703290600973836

Lin, T., Hsu, Y. \& Cheng, Y. (2011). Emerging innovative teacher education from situated cognition in a web-based environment. Turkish Online Journal of Educational Technology, 10 (2), 100- 112. (Eric Document Reproduction Service No, 93223).

Mannathoko, M. (2013). Does Teaching Practice Effectively Prepare Student-Teachers to Teach Creative and Performing Arts? The Case of Botswana. International Journal of Higher Education, 2 (2), 115- 121. http://dx.doi.org/10.5430/ijhe.v2n2p115

Pletka, B. (2007). Education the next generation: How to engage the students in the 21 ST century. Retrieved from: http://dx.doi.org/10.5860/choice

Precel, K., Eshet, Y. \& Alberton, Y. (2009). Pedagogical and Design Aspects of a Blended Learning Course. International Review of Research in Open and Distance learning, 10 (2). (Erıc Document Reproduction Service No, 844031).

Quevedo, A. (2011). Blended-learning Implementation in Undergraduate Teacher's Formation Courses: Difficulties from the Students' Point of View. The International Journal of Technology, Knowledge, and Society, 7 (2), $187-$ 200. http://dx.doi.org/10.18848/1832-3669/CGP/v07i02/56192

SEN, A. (2009). A Study on the Effectiveness of Peer Microteaching in a Teacher Education Program. Education and Science, 34 (151), 165- 174.

Shana, Z. (2009). Learning with Technology: Using Discussion Forums to Augment a Traditional-Style Class. Educational Technology \& Society, 12 (3), 214-228.

Smith, J., Groves, M., Bowed, B., Barber, A. (2012). Facilitating the Development of Study Skills through a Blended Learning Approach. International Journal of Higher Education, 1 (2), 108- 117. http://dx.doi.org/10.5430/ijhe.v1n2p108

Vogt, R., (2014). Experiences with Blended Learning Program Delivery for Apprenticeship Trades: A Case Study. International Journal of Higher Education, 3 (4), 85- 95. http://dx.doi.org/10.5430/ijhe.v3n4p85

\section{Note}

Note 1. https://www.facebook.com/groups/736912269721195/ 